\title{
Immediate Implant Placement in the Aesthetic Zone: A Multi- disciplinary Management - Case Report
}

\author{
Lovo María Tadea ${ }^{1 *}$ (D) Zárate Héctor ${ }^{2}$ (D), Rodríguez Karla ${ }^{3}$ and Martínez Daniel ${ }^{4}$ \\ ${ }^{1}$ Senior Resident, Department of Restorative Dentistry, Universidad Popular Autónoma del Estado de \\ Puebla, Mexico \\ ${ }^{2}$ Senior Resident, Department of Periodontology, Universidad Popular Autónoma del Estado de \\ Puebla, Mexico \\ ${ }^{3}$ Prosthodontist and Professor, Department of Restorative Dentistry, Universidad Popular Autónoma \\ del Estado de Puebla, Mexico \\ ${ }^{4}$ Periodontist and Professor, Department of Periodontology, Universidad Popular Autónoma del \\ Estado de Puebla, Puebla, Mexico
}

*Corresponding author: Lovo Maria Tadea, DDS, Senior Resident, Department of Restorative Dentistry, Universidad Popular Autónoma del Estado de Puebla, Calle 21 sur 1103, Barrio de Santiago, 72410 Puebla, Pue, Mexico

\begin{abstract}
Immediate implant placement in the esthetic zone, represents one of the biggest challenges in dentistry. It implies a multidisciplinary approach involving prosthetic and periodontal aspects to obtain long term stability, esthetic and functional results. A clinical case report is presented, taking into consideration periodontal and prosthetic management of an implant in the anterior zone, starting from the diagnosis, treatment plan, periodontal surgical procedures, provisionalization, and its definitive prosthetic rehabilitation.
\end{abstract}

\section{Introduction}

When the loss of a tooth located in the esthetic zone is inevitable, the need for a prosthetic replacement is necessary. Nowadays, there are different prosthetic options; implant-supported prostheses are one of the most reliable treatment alternatives. Also, the possibility of immediate or early loading represents a satisfactory solution for the patients and the clinician, always considering the patients' individual characteristics [1].

The survival rate and the restoration of function for this type of treatment are high. However, to guarantee an aesthetically successful result is not always possible, due to the dimensional changes that occur in hard and soft tissues after the loss of a tooth [2]. For this reason, they are considered as a "Complex SAC" from the surgical and prosthetic point of view according to the International Team for Implantology (ITI). This treatment modality requires a team protocol, where the main planning, surgical and prosthetic aspects are taken into account to obtain the desired result [3].

From a periodontal point of view, an understanding of the dentogingival complex and its counterpart the peri-implant mucosa, as well as its biological and physiological responses are equally important. In the same way, it is necessary to take into consideration the intrinsic characteristics of the patient, the surgical procedure, and prosthetic management [4].

Within prosthetic management, it is necessary to determine if immediate provisionalization is possible at the moment of the surgery. There is a greater esthetic and functional demand from patients. Thus, it is also necessary to satisfy the need for a faster treatment and reduce discomfort during the healing period [5].

The latest concept is "Non-functionally loaded immediate provisionalization"; defined as a load where the provisional restoration is adjusted to clear all occlusal contacts in centric and eccentric movements. The non- functionally loaded immediate provisionalization

Citation: Tadea LM, Héctor Z, Karla R, Daniel M (2020) Immediate Implant Placement in the Aesthetic Zone: A Multidisciplinary Management - Case Report. Int J Oral Dent Health 6:111. doi.org/10.23937/24695734/1510111

Accepted: July 14, 2020: Published: July 16, 2020

Copyright: (C) 2020 Tadea LM, Zárate H, et al. This is an open-access article distributed under the terms of the Creative Commons Attribution License, which permits unrestricted use, distribution, and reproduction in any medium, provided the original author and source are credited. 
protocol depends on optimal primary stability, adequate bone quality, and quantity. It will also depend on the alveolar anatomy after tooth extraction [6].

The main objective of immediate provisionalization is to preserve the gingival contours, maintain the natural emergence profile and to predict the final result. With this type of treatment, it is possible to place the final restoration 4 months after implant placement $[7,8]$.

\section{Case Report}

A 58-year-old female patient attended the periodontology department at Universidad Popular Autónoma del Estado Puebla (UPAEP) for consultation; "I want a full oral assessment". She did not report any important personal pathological history and was diagnosed with generalized periodontal disease stage I grade A [9]. After oral hygiene instructions, scaling and root planing, the patient was referred to a prosthetic assessment as part of the periodontal hygienic phase; in the restorative dentistry department, a clinical examination, intra- and extra-oral photography records, dental study models, and articulated diagnosis were carried out.

After prosthetic evaluation, a porcelain fused to metal crown with a metal cast post was removed in tooth 1.1 (Figure 1), which presented leakage and mismatched margins, as well as a dark coloration at the cervical margin level. Tooth 1.1 had no response to the vitality tests because it had a previous root canal treatment. When the restoration was removed, we could observe poor remaining tissue, dental walls with insufficient support and a compromised crown-root ratio, a Cone Beam was indicated to the patient, where insufficient remaining tissue was observed, poor root canal treatment and also a short root (Figure 2), due to these factors tooth extraction was indicated and an acrylic provisional was placed until the day of surgery.

A diagnostic wax-up and surgical guide were performed to continue with the surgical phase.

\section{Surgical phase}

The surgical protocol consisted of an atraumatic extraction of the central incisor tooth (1.1). With the help of a $15 \mathrm{C}$ scalpel blade, sharp dissection of the supracr-

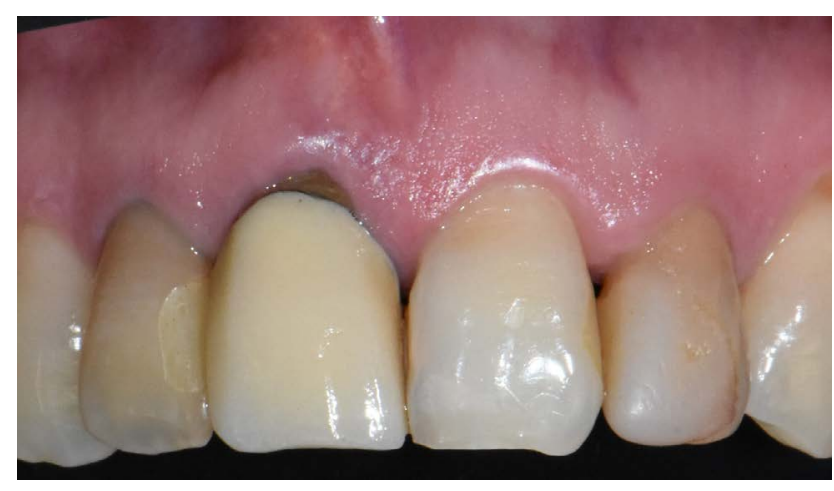

Figure 1: Initial situation. estal fibers, and a tunnel towards the vestibular plate was performed to obtain an "envelope" (Figure 3 and Figure 4), the extraction socket was carefully debrided and the osteotomy was prepared for the placement of a $3.9 \times 10 \mathrm{~mm}$ (V3 MIS) prosthetically guided implant

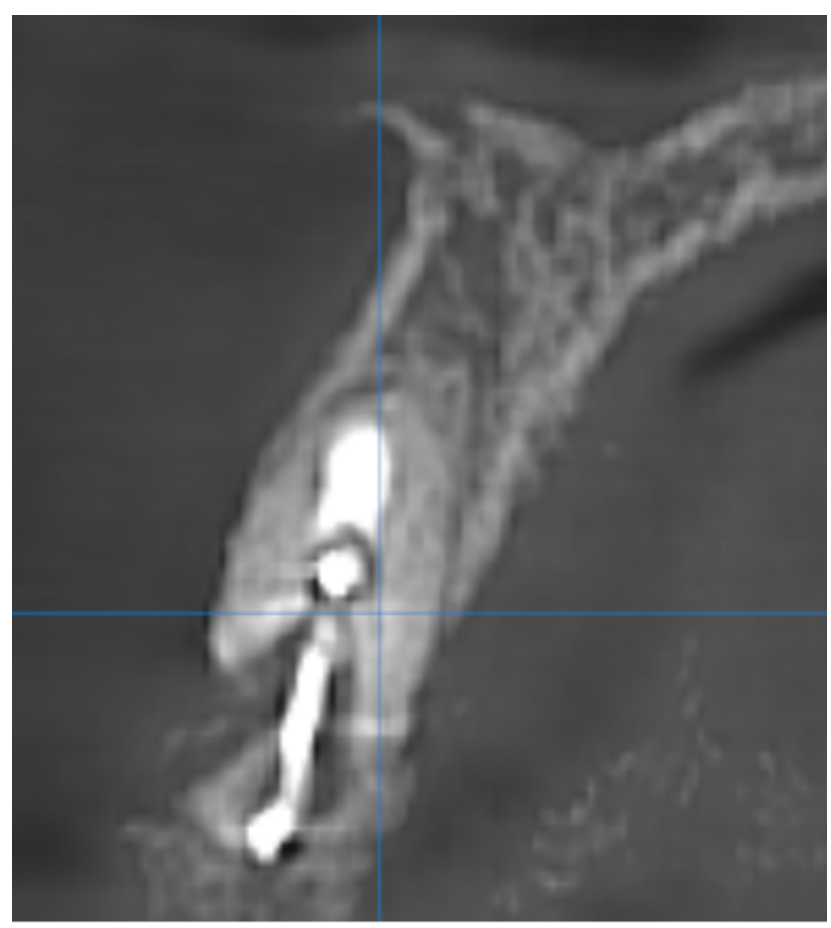

Figure 2: Image of area surrounding tooth 1.1 in cone beam CT.

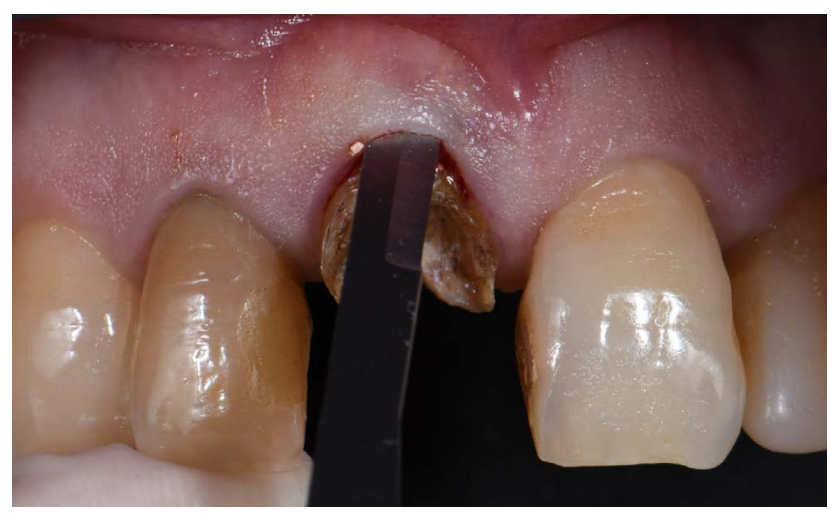

Figure 3: Sharp dissection.

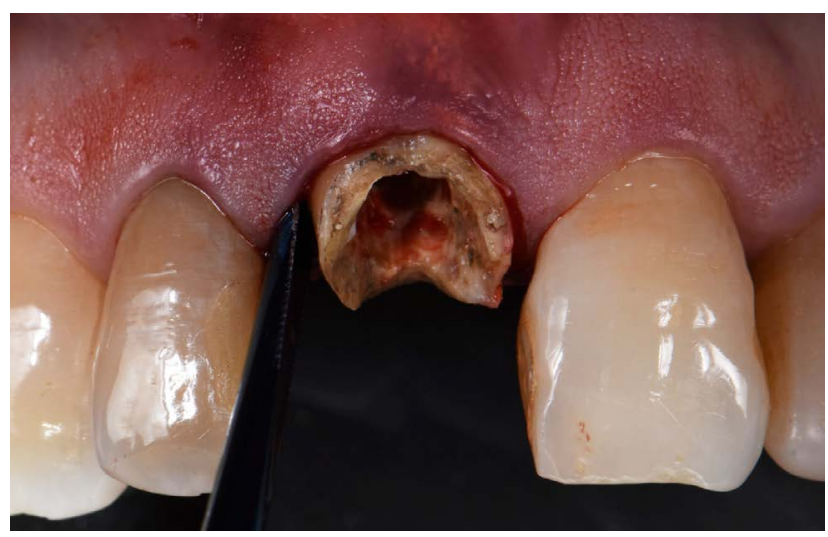

Figure 4: Atraumatic tooth extraction. 


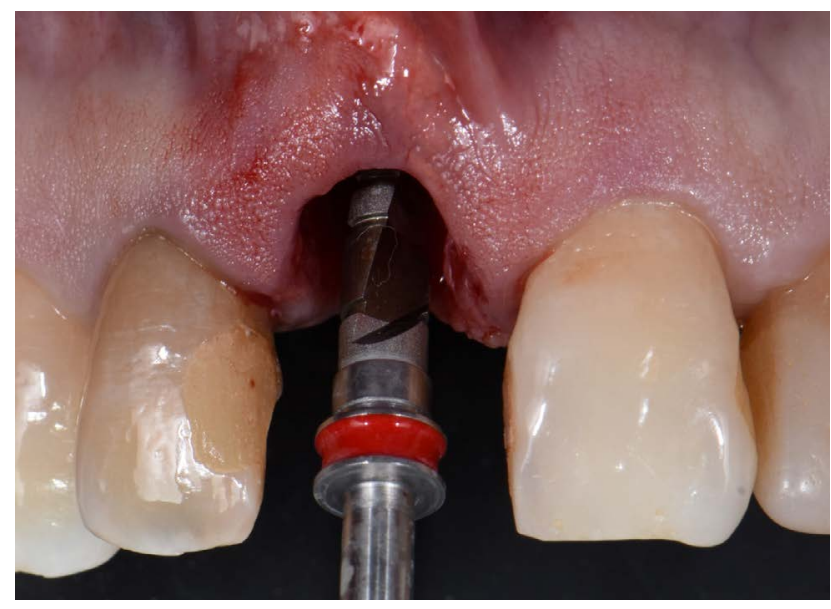

Figure 5: Implant osteotomy.

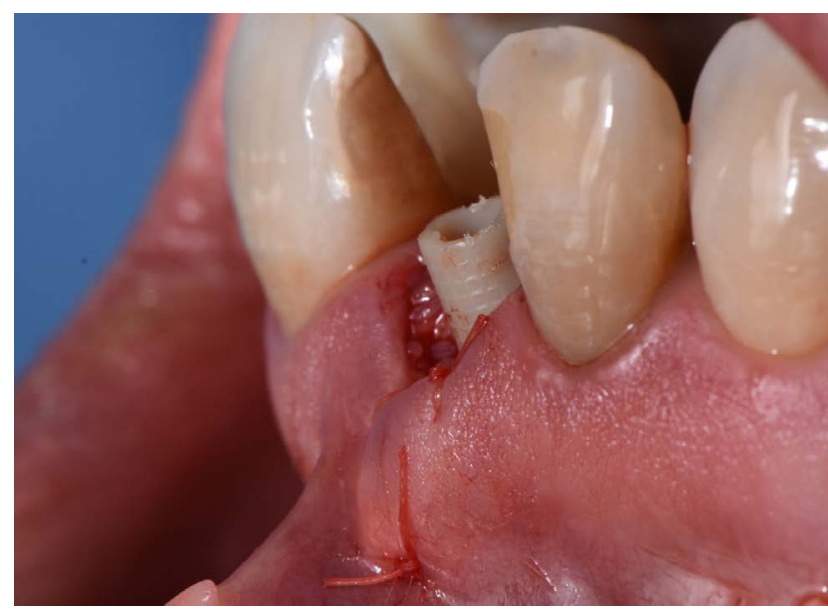

Figure 6: Soft and hard tissue graft.

(Figure 5), a $2 \mathrm{~mm}$ labial "gap" was obtained and the implant shoulder was placed $4 \mathrm{~mm}$ from the future gingival margin.

Primary stability was achieved in the apical third of the implant with a $35 \mathrm{~N}$ torque. The labial gap was filled with a small particle allograft, and a connective tissue graft from the palate $(10 \times 6 \mathrm{~mm})$ was taken and fixed in the previously created envelope with a 5-0 absorbable suture (Figure 6).

\section{Prosthetic phase}

Provisionalization: After implant placement, the provisional restoration was prepared. First, the milled PMMA provisional prosthesis was oriented and screwed onto the implant, it was modified with the help of a silicone guide taken from the diagnostic wax-up (Figure 7). When the correct height and contours were achieved, a flowable composite was injected into the subgingival contours. The critical and subcritical profiles were designed to shape the gingival tissues. After modifying the profile, the clinical crown portion was made with a bysacryl composite resin, using the same silicone guide.

The temporary restoration was polished to avoid irritation, gingival migration, and dental biofilm accumula-

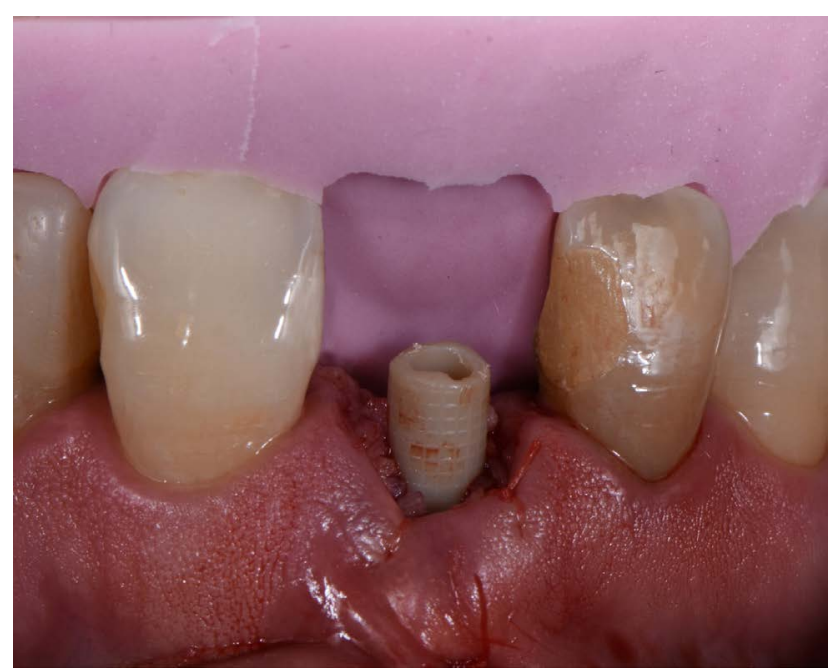

Figure 7: Silicone guide for provisional prosthesis.

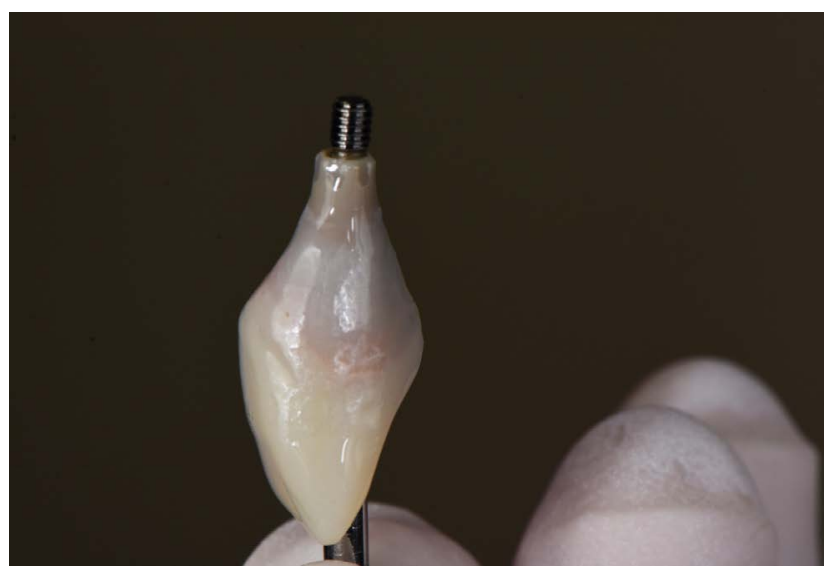

Figure 8: Provisional prosthesis.

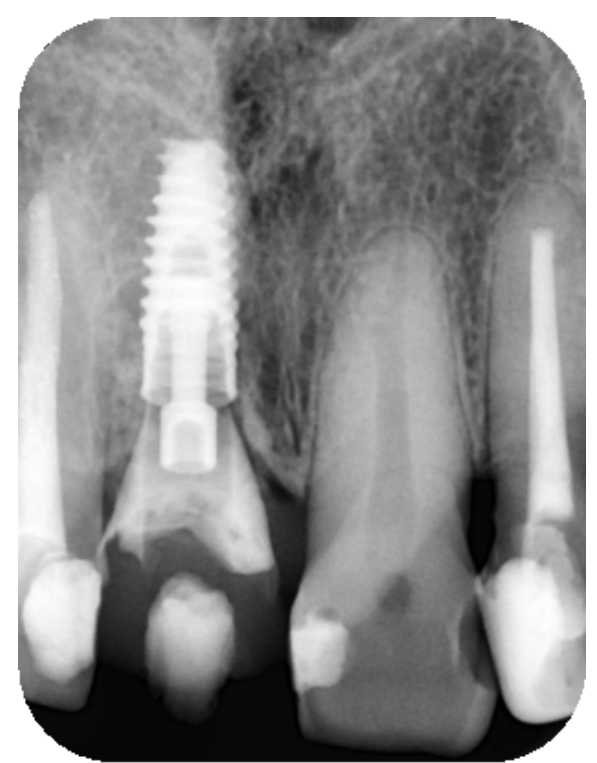

Figure 9: Post-operative control radiograph.

tion (Figure 8). The restoration was left with no occlusal contact with the opposing arch during centric and eccentric movements, a control radiograph was taken and post-operative indications were given (Figure 9). 


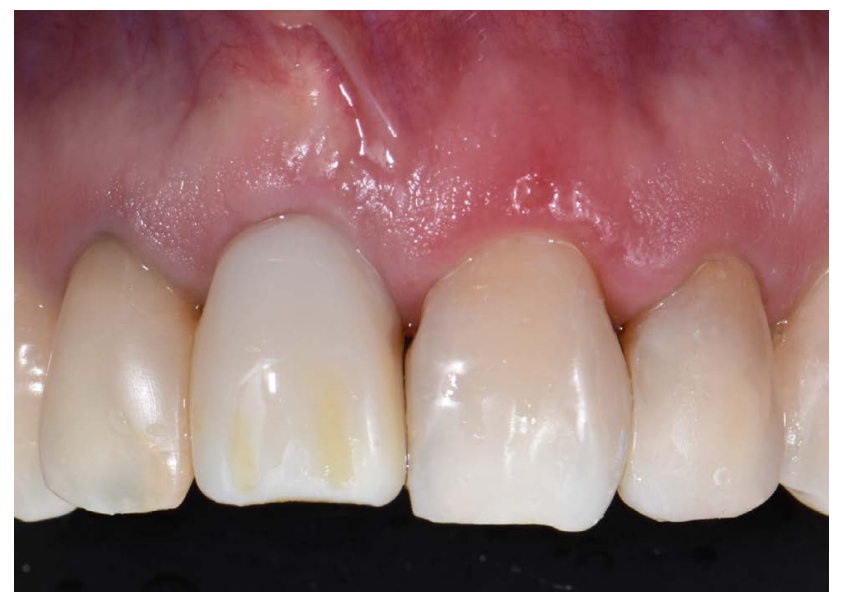

Figure 10: 4 months after surgery.

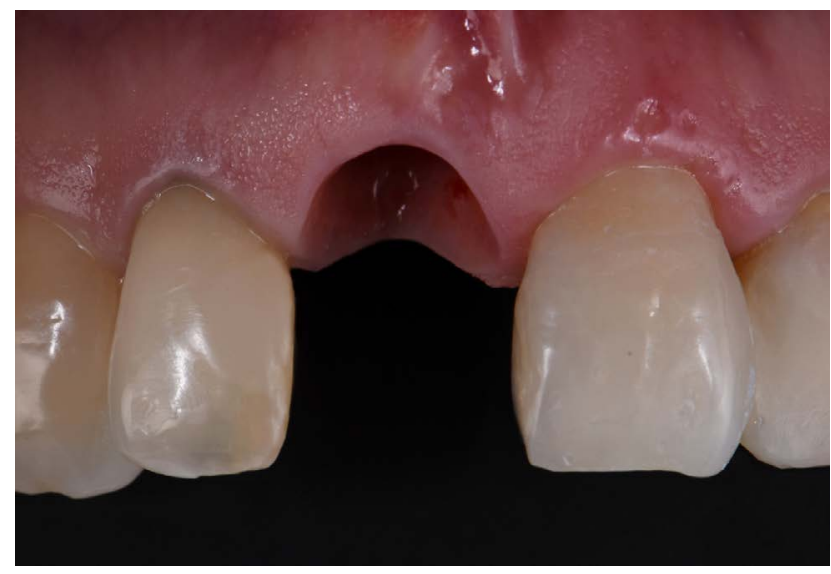

Figure 11: Emergence profile.

Antibiotic and analgesic therapies were indicated. Also, to avoid brushing the surgical area for 3 weeks and rinse with $0.12 \%$ chlorhexidine for 2 weeks. Likewise, a soft diet, and to avoid physical activities.

Definitive restoration: After 4 months, with adequate tissue healing (Figure 10), and the emergence profile correctly created (Figure 11), the final impression was taken. The following steps were used to make a custom-made impression coping:

1. The analog was submerged $2 / 3$ into addition silicone.

2. The implant provisional was connected to the analog abutment.

3. Light body impression material was injected around the provisional restoration connected to the analog.

4. Flowable composite was injected into the space between the impression material and impression coping.

This technique was used to maintain the complete emergence profile and prevent the gingival tissue from collapsing at the time of impression taking.

Subsequently, the custom-made impression coping was taken along into the mouth and it was connected into the implant without making any modifications as the profile was established with the use of the temporary prosthesis (Figure 12). A final impression was taken

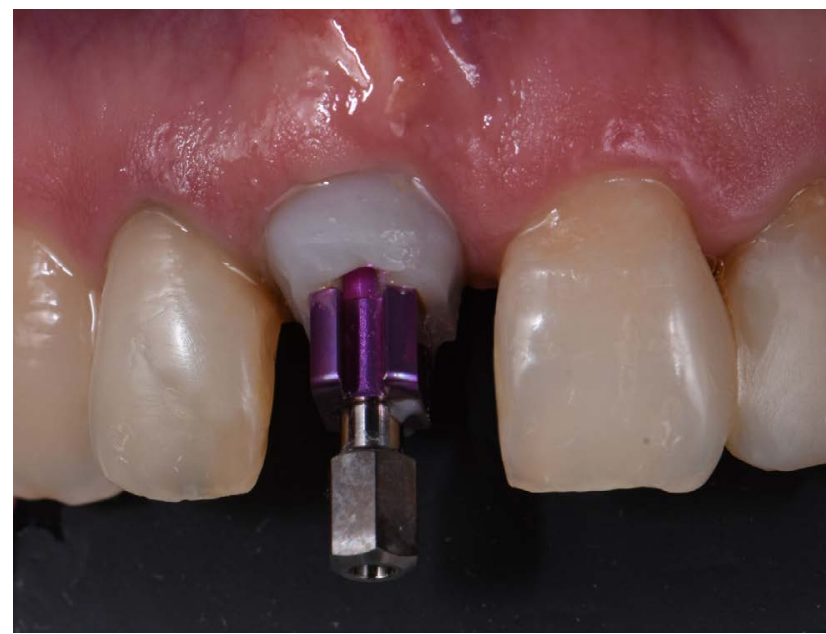

Figure 12: Open-tray impression abutment with flowable composite in the emergence profile to replicate provisional prosthesis.

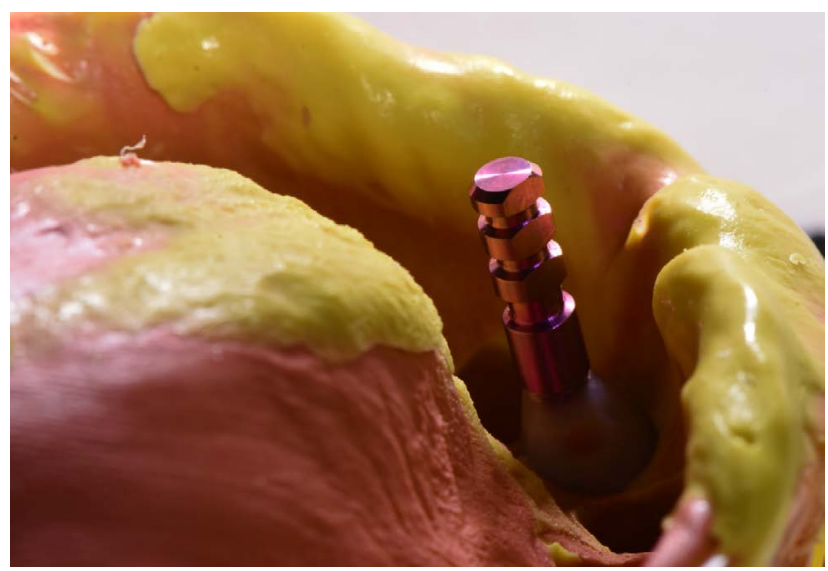

Figure 13: Final impression with addition silicone.

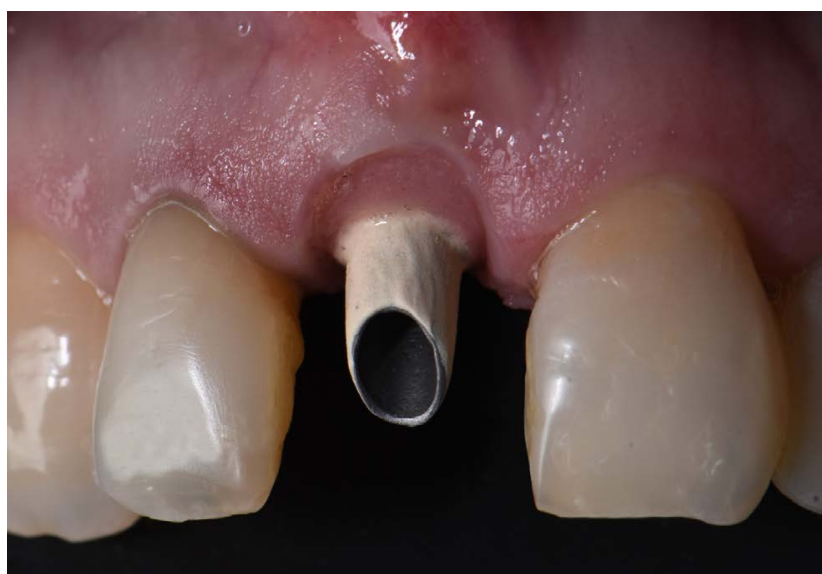

Figure 14: Opaqued CAD/CAM milled titanium abutment.

with an open tray impression technique using an addition silicone material (Figure 13).

The impression was cast with type IV dental stone, and the laboratory process was carried out. A CAD/CAM milled titanium straight prosthetic abutment was used. The profile was conformed with pink feldspathic porcelain for a more natural appearance, and the implant abutment was opaqued in the coronal portion for aes- 
thetic effects (Figure 14). A lithium disilicate crown was made, and it was stratified with feldspathic ceramic for aesthetic purposes.

The restoration was tried in the patient, and after approval, we proceeded to cementation. The titanium abutment was screwed with a torque of $35 \mathrm{~N}$ and the restoration was cemented with dual resin cement (Figure 15).

Monthly periodic appointments have been made for 2 years to observe treatment evolution; gingival tissue is intact, inflammation or bleeding has not been observed, color and thickness of gingival tissue are adequate, and the marginal levels have been maintained at an acceptable height in comparison to preclinical levels and adjacent teeth. In addition, patient's satisfaction with the final result (Figure 16).

\section{Discussion}

Immediate placement of dental implants has the advantage of reducing treatment time, and has a similar success to traditionally placed implants, likewise, offers the option of immediate provisionalization by allowing excellent aesthetic results and improving the patients' life quality $[10,11]$.

However, multiple publications have reported recession and loss of crestal bone height. Although the vestibular placement of implants was the main cause

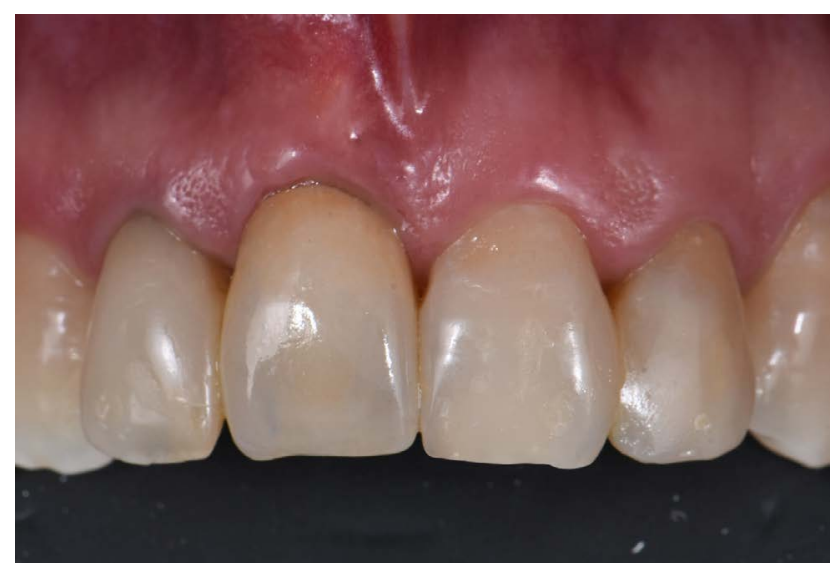

Figure 15: Cemented restoration.

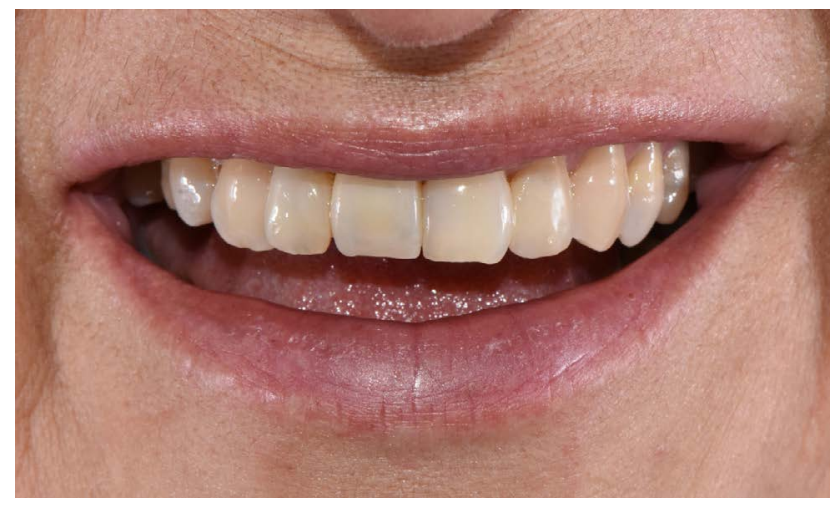

Figure 16: Final results. of recession, in most cases, the phenotype and factors that affect crestal bone such as traumatism, played an important role $[12,13]$.

A study in animals demonstrated that when implants are placed in a more palatal position, it is possible to maintain the vestibular wall and avoid the presence of recession, a commonly reported problem [14].

A drawback of implants with conventional technique is that after tooth extraction, certain bone resorption occurs, which can compromise the favorable position of the future implant and the restoration's esthetic outcome $[15,16]$. In 1989, a protocol that consisted of the post-extraction implant placement was introduced, such protocol has been adopted over the time due to the advantages it presents [17].

Nowadays, there are 4 types of implant placement protocols described and developed by the ITI, and their application will depend on the patient's clinical and radiographic preoperative planning [18]; this includes correct aesthetic diagnosis [19], atraumatic surgical techniques [20], surgical procedures for hard and soft tissue augmentations $[21,22]$ and a previously planned placement by computed tomography (CBTC) [23].

The reported survival rates for early and late implant protocols (type 2-4) range from 97.17 to 98\% [24], compared to immediate placement (type 1), which ranges from 93.80 to $100 \%[24,25]$. Therefore, it could be an option to consider through prior evaluation of the patient since it reduces the total treatment time and increases patient comfort.

Retrospective studies have reported that the immediate placement of implants and the opportunity to graft the residual gap, as well as the placement of an immediate provisional, allow us to maintain the height and thickness of the peri-implant mucosa $[2,26]$. In addition, the placement of a soft tissue graft contributes to the stability of the gingival levels and the increase in the contours of the soft tissues [21], mainly in patients with a thin phenotype, where this type of procedure allows the thickening of the same.

During implant placement, primary stability, Resonance Frequency Analysis (RFA), and insertion torque are often the most commonly used criteria to select loading protocols [27]. In a systematic review by Schrott in 2014 [28], a minimum torque of $30 \mathrm{Ncm}$ is indicated for immediate loading, a minimum stability ratio (ISQ) between 50 and 62 and an implant of at least 8 to 11 $\mathrm{mm}$ in length between the different studies reviewed; for immediate implant placement with immediate loading, a success rate of 87.5 to $100 \%$ can be expected [29]. In this case report, an insertion torque of $35 \mathrm{~N}$ was obtained with the placement of a $10 \mathrm{~mm}$ long implant. Therefore, immediate loading was possible, and an emergency profile with adequate dimensions was obtained. 


\section{Conclusion}

The introduction of predictable surgical and prosthetic techniques, as well as biocompatible materials have made it possible to meet the aesthetic and functional demands of patients. Post-extraction implants can be placed with the option of immediate loading. This has proven to be a breakthrough in modern dentistry.

It is necessary to have a careful case selection, correct diagnosis and an appropriate treatment plan to accomplish a successful result. It is also important to take into account if a bone graft to fill the gap between the implant and the socket walls is necessary, the need of soft tissue grafts in patients with a thin phenotype, assess the possibility of immediate loading depending on the primary stability of the implant, soft tissue management with the provisional prosthesis and the material of the final restoration to obtain the desired results.

\section{References}

1. Buser D, Martin W, Belser UC (2004) Optimizing esthetics for implant restorations in the anterior maxilla: Anatomic and surgical considerations. Int J Oral Maxillofac Implants 19: 43-61.

2. Tarnow DP, Chu SJ, Salama MA, Stappert CF, Salama H, et al. (2014) Flapless post extraction socket implant placement in the esthetic zone: Part 1. The effect of bone grafting and/or provisional restoration on facial-palatal ridge dimensional change-a retrospective cohort study. Int J Periodontics Restorative Dent 34: 323-331.

3. Levine RA, Ganeles J, Gonzaga L, Kan JK, Randel H, et al. (2017) 10 Keys for successful esthetic-zone single immediate implants. Compend Contin Educ Dent 38: 248-260.

4. Kan JYK, Rungcharassaeng K, Deflorian M, Weinstein T, Wang HL, et al. (2018) Immediate implant placement and provisionalization of maxillary anterior single implants. Periodontol 2000 77: 197-212.

5. Alani A, Corson M (2011) Soft tissue manipulation for single implant restorations. Br Dent J 211: 411-416.

6. De Rouck T, Collys K, Wyn I, Cosyn J (2009) Instant provisionalization of immediate single-tooth implants is essential to optimize esthetic treatment outcome. Clin Oral Implant Res 20: 566-570.

7. Morton D, Chen S, Martin W, Levine R, Buser D, et al. (2014) Consensus statements and recommended clinical procedures regarding optimizing esthetic outcomes in implant dentistry. Int J Oral Maxillofac Implants 29: 216-220.

8. Eric Rompen, Nicolas Raepsaet, Olivier Domken, Bernard Touati, Eric Van Dooren (2007) Soft tissue stability at the facial aspect of gingival converging abutments in the esthetic zone: A pilot clinical study. J Prosthet Dent 97: 119-125.

9. Caton JG, Armitage G, Berglundh T, Chapple ILC, Jepsen $S$, et al. (2018) A new classification scheme for periodontal and peri-implant diseases and conditions-Introduction and key changes from the 1999 classification. J Clin Periodontol 20: S1-S8.

10. Abu Hussein M, Abdulgani A, Watted N, Zahalka M (2015) Congenitally missing lateral incisor with orthodontics, bone grafting and single tooth implant: A case report. JDMS 14: 124-130.
11. Lesage B (2006) Improving implant aesthetics: Prosthetically generated papilla through tissue modeling with composite. Pract Proced Aesthet Dent 18: 257-263.

12. Abu-Hussein M, Abdulgani A, Musa B, Chlorokostas G (2014) The mandibular two-implant overdenture. JDAS 3: 58-62.

13. Schoenbaum TR (2015) Abutment emergence profile and its effect on peri-implant tissues. Compend Contin Educ Dent 36: 474-479.

14. Abdulgani Azzaldeen, Abusalih Ahmet, Hakki Ismail, Chlorokostas Georges, Abu-Hussein Muhamad (2015) Immediate loading with mini dental implants in the fully edentulous mandible. Int J Dent Health Sci 2: 1490-1499.

15. Seok-Woo Chang, Seung-Yun Shin, Jong-Rak Hong, Seung-Min Yang, Hyun-Mi Yoo, et al. (2009) Immediate implant placement into affected and non-infected extraction sockets: A pilot study. Oral Surg Med Oral Pathol Oral Radiol Endod 107: 197-203.

16. Parpaiola A, Sbricoli L, Guazzo R, Bressan E, Lops D (2017) Managing the peri-implant mucosa: A clinically reliable method for optimizing soft tissue contours and emergence profile. J Esthet Restor Dent 25: 317-323.

17. Lazarra RJ (1989) Immediate implant placement into extraction sites; surgical and restorative advantages. Int $\mathrm{J}$ Periodontics Restorative Dent 9: 332-343.

18. Buser D, Chappuis V, Belser UC, Chen S (2016) Implant placement post extraction in esthetic single tooth sites: When immediate, when early, when late? Periodontol 2000 73: 84-102.

19. Belser UC, Grütter L, Vailati F, Bornstein MM, Weber HP, et al. (2009) Outcome evaluation of early placed maxillary anterior single-tooth implants using objective esthetic criteria: A cross-sectional, retrospective study in 45 patients with a 2- to 4-year follow-up using pink and white esthetic scores. J Periodontol 80: 140-151.

20. Bashutski JD, Wang HL, Rudek I, Moreno I, Koticha T, et al. (2013) Effect of flapless surgery on single-tooth implants in the esthetic zone: A randomized clinical trial. J Periodontol 84: 1747-1754.

21. Poskevicius L, Sidlauskas A, Galindo-Moreno P, Juodzbalys $G$ (2017) Dimensional soft tissue changes following soft tissue grafting in conjunction with implant placement or around present dental implants: A systematic review. Clin Oral Implants Res 28: 1-8.

22. Rosa AC, da Rosa JC, Dias Pereira LA, Francischone CE, Sotto-Maior BS (2016) Guidelines for selecting the implant diameter during immediate implant placement of a fresh extraction socket: A case series. Int $\mathrm{J}$ Periodontics Restorative Dent 36: 401-407.

23. Kan JY, Roe P, Rungcharassaeng K, Patel RD, Waki T, et al. (2011) Classification of sagittal root position in relation to the anterior maxillary osseous housing for immediate implant placement: A cone beam computed tomography study. Int J Oral Maxillofac Implants 26: 873-876.

24. Bassir SH, El Kholy K, Chen CY, Lee KH, Intini G (2019) Outcome of early dental implant placement versus other dental implant placement protocols: A systematic review and meta-analysis. J Periodontol 90: 493-506.

25. Bhola M, Jacobs LC, Kolhatkar S (2015) Immediate implants for aesthetic success: New guidelines. J Int Clin Dent Res Organ 7: 138-147.

26. Chu SJ, Salama MA, Garber DA, Salama H, Sarnachiaro 
GO, et al. (2015) Flapless postextraction socket implant placement, Part 2: The effects of bone grafting and provisional restoration on peri-implant soft tissue height and thickness- a retrospective study. Int J Periodontics Restorative Dent 35: 803-809.

27. Gallucci GO, Benic GI, Eckert SE, Papaspyridakos P, Schimmel M, et al. (2014) Consensus statements and clinical recommendations for implant loading protocols. Int J Oral Maxillofac Implants 29: 287-290.
28. Schrott A, Riggi-Heiniger M, Maruo K, Gallucci GO (2014) Implant loading protocols for partially edentulous patients with extended edentulous sites--a systematic review and meta-analysis. Int J Oral Maxillofac Implants 29: 239-255.

29. Gallucci GO, Hamilton A, Zhou W, Buser D, Chen S (2018) Implant placement and loading protocols in partially edentulous patients: A systematic review. Clin Oral Implants Res 16: 106-134 